\title{
Inflammatory and stress markers predicting pneumonia, outcome, and etiology in patients with stroke
}

\author{
Biomarkers for predicting pneumonia, functional outcome, and \\ death after stroke
}

Benjamin Hotter, MD, Sarah Hoffmann, MD, Lena UIm, MD, Joan Montaner, MD, Alejandro Bustamante, MD, Christian Meisel, MD, and Andreas Meisel, MD

Neurol Neuroimmunol Neuroinflamm 2020;7:e692. doi:10.1212/NXI.0000000000000692

\author{
Correspondence \\ Dr. Hotter \\ benjamin.hotter@charite.de
}

\section{Abstract}

\section{Objective}

Prognosis of stroke is negatively affected by complications, in particular stroke-associated pneumonia (SAP). We hypothesized that inflammatory and stress biomarkers predict SAP during hospitalization and outcome 3 months after stroke.

\section{Methods}

We pooled the clinical data of 2 acute stroke studies with identical assessment: the STRoke Adverse outcome is associated WIth NoSoKomial Infections (STRAWINSKI) and PREDICT studies. Measurement of biomarkers (ultrasensitive procalcitonin [PCTus]; midregional pro-adrenomedullin; midregional pro-atrial natriuretic peptide [MRproANP]; ultrasensitive copeptin [CPus]; C-terminal pro-endothelin) was performed from serum samples drawn on the first 4 days of hospital admission.

\section{Results}

The combined cohort consists of 573 cases with available backup samples to perform the analysis. SAP was associated with increased admission and maximum levels of all biomarkers. Furthermore, all biomarkers were associated with death and correlated with functional outcome 3 months after stroke. The multivariate logistic regression model retained ultrasensitive CPus and PCTus beyond clinical risk factors for predicting SAP, improving the receiver operating characteristic area under the curve (AUC) from 0.837 to 0.876 . In contrast, the biomarkers did not improve the prediction of death and functional outcome in the multivariate model. Cardioembolic strokes were significantly associated with higher values of all biomarkers, whereas discrimination was best for MRproANP (AUC $=0.811$ for maximum value).

\section{Conclusions}

The tested biomarkers are associated with SAP and poor functional outcome. However, these biomarkers only slightly improve prediction of SAP and do not improve long-term outcome prediction over clinical parameters. MRproANP showed the best discrimination for identifying cardioembolic stroke, warranting further studies to confirm our finding.

\section{Clinical trial registration}

clinicaltrials.gov NCT01264549 and NCT01079728.

From the Charité - Universitätsmedizin Berlin (B.H., S.H., L.U., A.M.), Corporate Member of Freie Universität Berlin, Humboldt-Universität zu Berlin, and Berlin Institute of Health; Center for Stroke Research Berlin, NeuroCure Clinical Research Center and Department of Neurology, Berlin; Friedrich Loeffler Institute of Medical Microbiology (L.U.), University Medicine Greifswald, Greifswald, Germany; Neurovascular Research Laboratory (J.M., A.B.), Vall d'Hebron Institut de Recerca, Barcelona; Stroke Research Program (J.M.), Institute of Biomedicine of Seville, IBiS/Hospital Universitario Virgen del Rocío/CSIC/University of Seville; Department of Neurology (J.M.), Hospital Universitario Virgen Macarena, Spain; and Department of Medical Immunology (C.M.), Charité University Medicine and Labor Berlin - Charité Vivantes GmbH, Berlin, Germany. 


\section{Glossary}

ANP = atrial natriuretic peptide; AUC = area under the curve; COPD = chronic obstructive pulmonary disease; CPus = ultrasensitive copeptin; CTproET = C-terminal pro-endothelin; MRproANP = midregional pro-ANP; $\mathbf{m R S}=$ modified Rankin Scale; NI = no infection; NIHSS = NIH Stroke Scale; NPV = negative predictive value; $\mathbf{P C T}=$ procalcitonin; PCTus = ultrasensitive procalcitonin; $\mathbf{P P V}=$ positive predictive value; $\mathbf{R O C}=$ receiver operating characteristic; $\mathbf{S A P}=$ stroke-associated pneumonia; STRAWINSKI $=$ STRoke Adverse outcome is associated WIth NoSoKomial Infections; UTI $=$ urinary tract infection.

Stroke is among the leading causes of death, and its outcome is strongly depending on complications. ${ }^{1}$ Infections, in particular pneumonia, are one of the standout risk factors for poor outcome after stroke. The prediction of outcome and complications remains challenging and relies on age, severity of stroke, and other risk factors for pneumonia, e.g., dysphagia. $^{2}$

Stroke induces a suppression of immune responses via activation of the autonomic nervous system and stress axis, significantly contributing to the development of strokeassociated pneumonia (SAP). ${ }^{3}$ Biomarkers of immunity, stress, and inflammation are considered to predict strokeassociated infections and even the outcome of stroke itself. ${ }^{4}$ The development of biomarkers to indicate outcome and complications such as infections would help to triage monitoring needs and preventive anti-infective treatment for patients with stroke at risk and would allow for early prognosis of long-term outcome. So far, no single biomarker or biomarker pattern predicting infections or outcome with a sufficient negative and positive predictive value (PPV) has been identified. $^{5}$

We hypothesized that a set of inflammatory and stress biomarkers predict SAP and functional outcome after stroke: Procalcitonin has been associated with post-stroke infections before. ${ }^{6,7}$ Midregion pro-adrenomedullin has been previously associated with stroke-associated infections ${ }^{8}$ and functional outcome after stroke. ${ }^{9,10}$ Copeptin, a hypothalamic stress hormone, has been associated with higher risk of all-cause mortality, poor functional outcome after ischemic stroke, and stroke-associated infections. ${ }^{6,11-13}$ Midregion pro-atrial natriuretic peptide (ANP) is a marker of hemodynamic stress and has been associated with a higher risk for occurrence of ischemic stroke. ${ }^{14,15} \mathrm{C}$-terminal pro-endothelin-1 (CTproET) is a strong vasoconstrictor influenced by age, renal function, and hemodynamic parameters. ${ }^{13}$

In a large cohort of patients with stroke based on the PREDICT and STRoke Adverse outcome is associated WIth NoSoKomial Infections (STRAWINSKI) studies, we tested these biomarkers for their properties in predicting SAP during acute hospitalization and death and functional outcome 3 months after stroke onset. Furthermore, we explored the relationship of these biomarkers to different stroke etiologies.

\section{Methods}

\section{Standard protocol approvals, registrations, and patient consents}

We pooled the clinical data of 2 multicentric acute stroke studies with identical data assessment (case report forms): the STRAWINSKI and PREDICT studies (clinicaltrials.gov NCT01264549 and NCT01079728). Both studies received approval by the institutional ethics committee and data protection office of Charité Universitätsmedizin Berlin. Every patient or their legal representative gave written informed consent to participate in the studies. Protocol details and primary outcome data of both studies have been previously published. ${ }^{7,14,15}$ Briefly, both studies recruited acute ischemic stroke patients to investigate the prediction (PREDICT) and eventually procalcitonin (PCT)-guided immediate early treatment (STRAWINSKI) of SAP. Selection criteria for PREDICT were less selective (inclusion of any ischemic stroke with a minimum NIH Stroke Scale [NIHSS] score of 1 and within 36 hours after event), leading to a larger but less severely affected cohort, whereas STRAWINSKI included patients with a minimum NIHSS score of 9 and consequently more frequent SAP. In both studies, SAP was defined according to the PISCES criteria. ${ }^{5}$

\section{Biomarker sampling}

Serum samples were analyzed for levels of the following biomarkers using fluorescent immunoassays (BRAHMS GmbH/ Thermo Fisher Scientific, Hennigsdorf, Germany): midregional pro-ANP (MRproANP), midregional pro-adrenomedullin (MRproADM), CTproET, ultrasensitive copeptin (CPus), and ultrasensitive PCT (PCTus). All measurements were performed on the automated BRAHMS KRYPTOR compact PLUS analyzer according to the manufacturer's protocol. The lower limits of quantification were $4.5 \mathrm{pmol} / \mathrm{L}$ for MRproANP, $0.05 \mathrm{nmol} / \mathrm{L}$ for MRproADM, $3 \mathrm{pmol} / \mathrm{L}$ for CTproET, 1.9 $\mathrm{pmol} / \mathrm{L}$ for CPus, and $0.02 \mu \mathrm{g} / \mathrm{L}$ for PCTus. Measurement was performed from blood samples drawn daily during the first 4 days of hospital admission. Admission blood samples were drawn as soon as possible, but at least within 36 or 40 hours within the ischemic event in PREDICT and STRAWINSKI, respectively. ${ }^{715,18}$

\section{Biometrics}

Standard descriptive sum statistics were performed to describe demographics and stroke characteristics and biomarker results. We split the cohort into patients having SAP including sepsis, urinary tract infection only (UTI), and no infection (NI). 
Associations were analyzed using the Fisher exact test, independent sample Mann-Whitney $U$ test, and Spearman correlation, depending on the character of variables. To quantify the effect size of nonparametric associations, we calculated Cohen $\mathrm{r}$ via the aforementioned Mann-Whitney $U$ test. Typically, effects larger than $0.1,0.3$, and 0.5 are deemed small, moderate, and large, respectively. Spearman $\rho$ larger than 0.3 , 0.6 , and 0.8 is typically considered a fair, moderate, or very strong correlation, respectively. For multivariate logistical regression with backward variable selection to predict SAP and death after 3 months, we included all variables showing association in univariate testing at an alpha level of $p=0.1$. Receiver operating characteristic (ROC) curves were calculated based on probabilities of outcome events predicted by a logistic multivariate regression analysis. All statistics were performed using SPSS (version 24.0; IBM, Armonk, NY).

Table 1 Demographics and stroke characteristics for the total cohort and patients having SAP, UTI only, or no infection

\begin{tabular}{|c|c|c|c|c|c|c|c|c|}
\hline & Total & & SAP & & UTI only & & No infection & \\
\hline n (\%) & $573(100)$ & Missing & $74(12.9)$ & Missing & $29(5.1)$ & Missing & $470(82.0)$ & Missing \\
\hline Sex, $n(\%)$ female & $269(47.0)$ & 1 & 36 (48.6) & 0 & $23(79.3)$ & 0 & $210(44.8)$ & 1 \\
\hline Age, y, mean (SD) & $72.1(12.2)$ & 0 & $76.8(9.7)$ & 0 & $78.0(12.7)$ & 0 & $71.0(12.2)$ & 0 \\
\hline Admission NIHSS score & $8(3-14)$ & 8 & $15(13-20)$ & 0 & $12(6.5-19)$ & 0 & $5.5(3-12)$ & 8 \\
\hline Thrombolysis, n (\%) & $218(45.9)$ & 98 & 34 (49.3) & 5 & 12 (44.4) & 2 & $172(45.4)$ & 91 \\
\hline \multicolumn{9}{|l|}{ Risk factors, n (\%) } \\
\hline HTN & $473(84.0)$ & 10 & $67(90.5)$ & 0 & $23(79.3)$ & 0 & $383(83.3)$ & 10 \\
\hline Hypercholesterolemia & $295(53.4)$ & 21 & $28(40.0)$ & 4 & $14(50.0)$ & 1 & $253(55.7)$ & 13 \\
\hline COPD & $50(10.6)$ & 101 & $11(16.9)$ & 9 & $2(7.7)$ & 3 & $37(9.7)$ & 89 \\
\hline Diabetes & $155(28.0)$ & 19 & $26(35.6)$ & 1 & $7(25.9)$ & 2 & $122(26.9)$ & 16 \\
\hline Dysphagia & $235(45.0)$ & 51 & $59(85.5)$ & 5 & $18(62.1)$ & 0 & $158(37.3)$ & 46 \\
\hline Previous stroke & $120(21.9)$ & 24 & $15(21.1)$ & 3 & $6(22.2)$ & 2 & $99(22.0)$ & 19 \\
\hline Smoking & $125(26.0)$ & 92 & $12(19.7)$ & 13 & $5(22.7)$ & 7 & $108(27.1)$ & 72 \\
\hline Atrial fibrillation & $201(36.4)$ & 21 & $38(52.1)$ & 1 & $9(33.3)$ & 2 & $154(34.1)$ & 18 \\
\hline \multicolumn{9}{|l|}{ Toast } \\
\hline Large artery occlusion & $173(30.2)$ & & $20(27.0)$ & & $11(37.9)$ & & $142(30.2)$ & \\
\hline Cardioembolism & $208(36.5)$ & & $37(50.0)$ & & $8(27.6)$ & & 164 (34.9) & \\
\hline Small artery disease & $52(9.1)$ & & $0(0)$ & & $5(17.2)$ & & $47(10.0)$ & \\
\hline Other etiology & $19(3.3)$ & & $1(1.4)$ & & $0(0)$ & & $18(3.8)$ & \\
\hline Unknown etiology & $120(20.9)$ & & $16(21.6)$ & & $5(17.2)$ & & $99(21.1)$ & \\
\hline 90-day mortality, n (\%) & $61(12.2)$ & 73 & $25(33.8)$ & 2 & $2(7.4)$ & 2 & $34(8.5)$ & 69 \\
\hline mRS score at discharge & $3(1-4)$ & 24 & $5(4-5)$ & 1 & $4(3-5)$ & 0 & $2(1-4)$ & 23 \\
\hline mRS score after $90 \mathrm{~d}$ & $3(1-4)$ & 95 & $5(4-6)$ & 10 & $4(2-5)$ & 4 & $2(1-4)$ & 81 \\
\hline BI after $90 \mathrm{~d}$ & $95(55-100)$ & 146 & $35(11.25-60)$ & 34 & $52.5(15-90)$ & 5 & $95(70-100)$ & 107 \\
\hline \multicolumn{9}{|l|}{ Infections, n (\%) } \\
\hline Pneumonia & 114 (19.9) & 33 & $74(100)$ & & $0(0)$ & & $0(0)$ & \\
\hline Sepsis & $3(0.5)$ & 33 & $3(4.1)$ & & $0(0)$ & & $0(0)$ & \\
\hline UTI & $36(6.3)$ & 32 & $7(9.5)$ & & $29(100)$ & & $0(0)$ & \\
\hline Any infection & $141(24.6)$ & 32 & $74(100)$ & & $29(100)$ & & $0(0)$ & \\
\hline
\end{tabular}

Abbreviations: $\mathrm{BI}=$ Barthel Index; $\mathrm{COPD}=$ chronic obstructive pulmonary disease; $\mathrm{HTN}=$ arterial hypertension; $\mathrm{IQR}=$ interquartile range; $\mathrm{mRS}=$ modified Rankin Scale; SAP = stroke-associated pneumonia; TOAST = Trial of ORG 10172 classification; UTI = urinary tract infection.

All numbers given as median (IQR) unless stated explicitly otherwise. 


\section{Data availability}

Any data not published within the article are available in anonymized form by request from any qualified investigator.

\section{Results}

The combined cohort of PREDICT and STRAWINSKI patients consists of 712 cases, 29 of which representing patients participating in both studies. In 110 of the remaining subjects, there were no sufficient backup blood samples. Age and sex did not differ in these patients without backup blood samples, but they were significantly less severely impaired by stroke at admission (lower NIHSS scores) and showed a higher rate of infections (data not shown). We restricted our analysis to the final cohort of 573 patients. Forty-seven percent of these patients were female; the mean age of this cohort was 72.1 years. Median stroke severity at admission was 8 (interquartile range [IQR] 3-14) as measured by the NIHSS. At 3 months, the median modified Rankin Scale (mRS) score was 3 (IQR 1-4), and 12\% of patients had died. A total of $12.9 \%$ had SAP, $5.1 \%$ had UTI only, and $82.0 \%$ did not acquire any infection (NI). These and further demographics and stroke characteristics are given in table 1 , and median values of biomarkers at admission or their maximum during hospitalization are represented in table 2 . The course of biomarker changes over the first 4 days is shown in figure e-1 (links.lww. com/NXI/A198).

In univariate analysis, SAP and NI were associated with increased or decreased admission and maximum levels of all biomarkers, respectively (table 2 ). The only biomarker associated with UTI was MRproADM (admission and maximum levels; data not shown). Furthermore, all biomarkers were associated with death 3 months after stroke. Discrimination for prediction of SAP (figure 1, A and B) and death (figure 1, C and D) was moderate to strong. Functional outcome as measured by the mRS 3 months after stroke was weakly (PCT) to moderately (all other biomarkers) correlated with biomarker levels on admission (table 2, figures e-2 and e-3, links.lww.com/ NXI/A198). We tested risk factors for death and SAP to select the following predictors for multivariate testing based on a univariate alpha level of 0.1 : dysphagia, hypercholesterolemia, atrial fibrillation, stroke etiology, chronic obstructive pulmonary disease (COPD), and admission NIHSS score for a prediction model of SAP; age, sex, hypertension, dysphagia, smoking, atrial fibrillation, stroke etiology, and admission NIHSS score for a prediction model of death at 3 months (data not shown).

The multivariate logistic regression model for SAP retained admission NIHSS score, COPD, dysphagia, hypercholesterolemia, and CPus and PCTus as independent predictors (table 3). The sensitivity and specificity of prediction was plotted as an ROC curve with an area under the curve of 0.876 , signifying excellent discrimination. A model without the investigated biomarkers reached an ROC area under the curve of 0.837 , signifying only little added discrimination by
Table 2 Biomarkers for the total cohort and depending on the occurrence of SAP during initial hospitalization and death and the mRS score 90 days after stroke

\begin{tabular}{|c|c|c|c|}
\hline & SAP $^{a}$ & $\begin{array}{l}\text { Death at } \\
\text { day } 90^{a}\end{array}$ & $\begin{array}{l}\text { mRS score } \\
\text { at day } 90^{b}\end{array}$ \\
\hline \multicolumn{4}{|l|}{ Admission values } \\
\hline \multicolumn{4}{|l|}{ MRproANP } \\
\hline $153.5(86.4-255.7)$ & 0.27 & 0.33 & 0.411 \\
\hline \multicolumn{4}{|l|}{ MRproADM } \\
\hline $0.80(0.63-1.08)$ & 0.24 & 0.30 & 0.395 \\
\hline \multicolumn{4}{|l|}{ CTproET } \\
\hline $65.9(52.9-89.4)$ & 0.21 & 0.26 & 0.362 \\
\hline \multicolumn{4}{|l|}{ CPus } \\
\hline $10.4(6.1-24.4)$ & 0.32 & 0.29 & 0.427 \\
\hline \multicolumn{4}{|l|}{ PCTus } \\
\hline $0.035(0.023-0.052)$ & 0.16 & 0.19 & $0.158^{c}$ \\
\hline
\end{tabular}

\section{Maximum values}

\begin{tabular}{llll}
\hline \multicolumn{1}{l}{ MRproANP } & & \\
\hline $\mathbf{1 7 7 . 9}(\mathbf{1 0 1 . 4 - 3 0 6 . 1 )}$ & 0.29 & 0.34 & 0.437 \\
\hline MRproADM & & & \\
\hline $\mathbf{0 . 8 8}$ (0.70-1.20) & 0.33 & 0.37 & 0.483 \\
\hline CTproET & & & \\
\hline $\mathbf{7 3 . 0}$ (58.1-96.9) & 0.24 & 0.31 & 0.393 \\
\hline CPus & & & 0.448 \\
\hline $\mathbf{1 5 . 1}$ (8.5-31.7) & 0.34 & 0.28 & \\
\hline PCTus & & & 0.342 \\
\hline $\mathbf{0 . 0 4 8}(\mathbf{0 . 0 3 3 - 0 . 0 7 2 )}$ & 0.32 & 0.28 \\
\hline
\end{tabular}

Abbreviations: $\mathrm{CP}$ us = ultrasensitive copeptin; $\mathrm{CTProET}=\mathrm{C}$-terminal proendothelin; IQR = interquartile range; MRproADM = midregional pro-adrenomedullin; MRproANP = midregional pro-atrial natriuretic peptide; $\mathrm{mRS}=$ modified Rankin Scale; PCTus = ultrasensitive procalcitonin; SAP = strokeassociated pneumonia.

All numbers given as median (IQR) in the unit $\mathrm{pg} / \mathrm{mL}$.

a Values given are effect sizes $r$ of association obtained by Mann-Whitney $U$ test with $p$ values of $<0.001$ each.

${ }^{\text {b }}$ Values given are Spearman kappa with a $p$ value of $<0.001$ except where $p$ was 0.001 .

${ }^{c} p$ was 0.001 .

CPus and PCTus (data not shown). The multivariate model for prediction of death at day 90 after stroke retained the independent predictors age and admission NIHSS score (table 3 ). The sensitivity and specificity of prediction was plotted as an ROC curve with an area under the curve of 0.880 , signifying excellent discrimination.

Cardioembolic strokes showed higher values for all examined biomarkers ( $p$ values obtained via Mann-Whitney $U$ test). Association effect sizes with admission samples for 
Figure 1 ROC for prediction of SAP or death 90 days after stroke for admission ( $A$ and C) and maximum biomarker levels (B and D)

A. Occurence of SAP

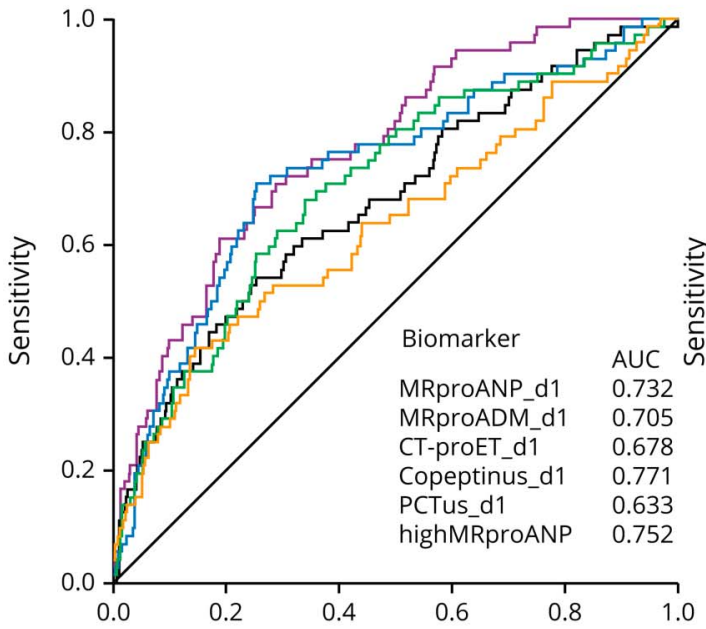

C. Deceased on day 90

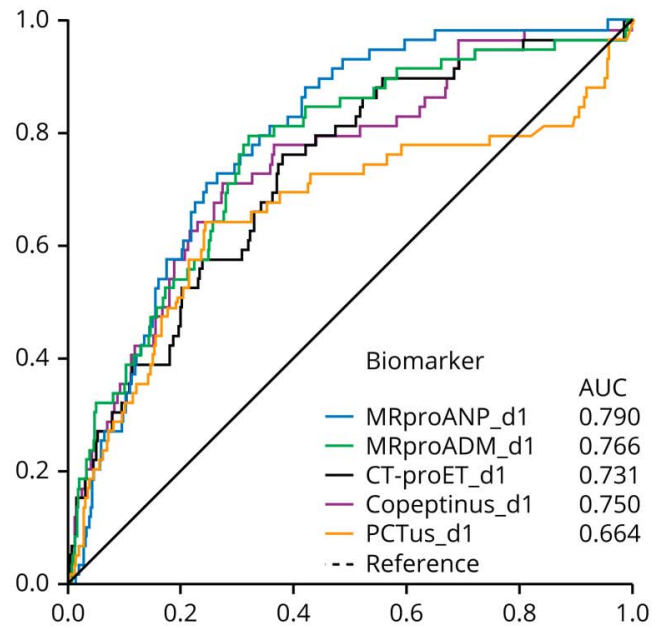

B. Occurence of SAP

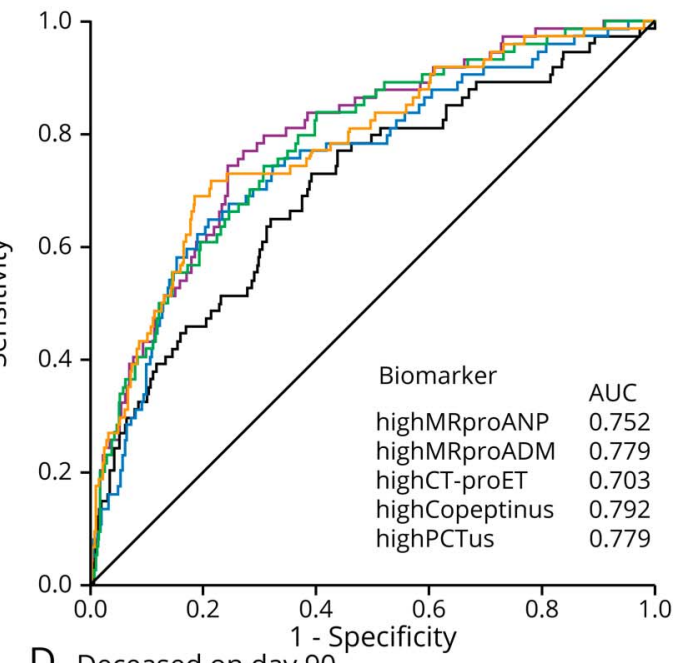

D. Deceased on day 90

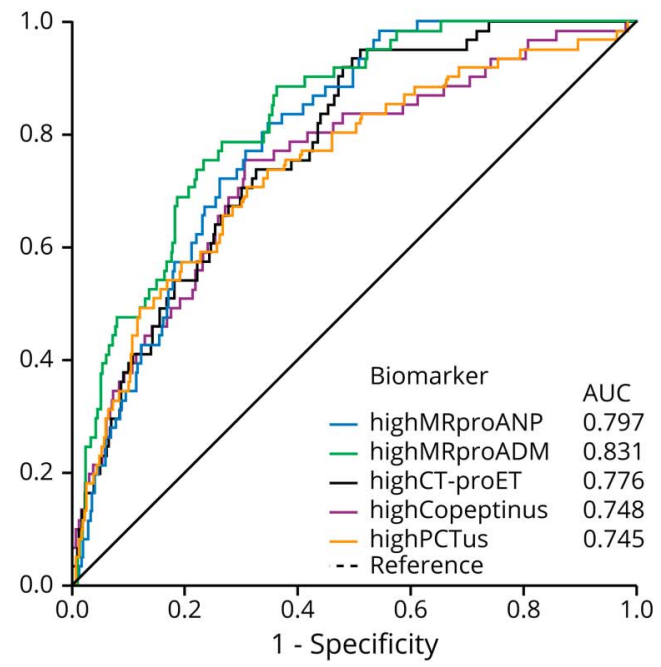

$\mathrm{AUC}=$ area under the curve; $\mathrm{CTproET}=\mathrm{C}$-terminal pro-endothelin; $\mathrm{MRproADM}=$ midregional pro-adrenomedullin; $\mathrm{MRproANP}=$ midregional pro-ANP; $\mathrm{PCTus}$ $=$ ultrasensitive procalcitonin; SAP = stroke-associated pneumonia.

MRproANP, MRproADM, CTproET, CPus, and PCTus were $0.48,0.31,0.33,0.20$, and 0.08 , respectively. Association with maximum values over the course of the first 4 consecutive days after stroke had effect sizes of $0.52,0.34$, $0.37,0.24$, and 0.14 for MRproANP, MRproADM, CTproET, CPus, and PCTus, respectively. The sensitivity and specificity of prediction was plotted as an ROC curve with areas under the curve in the range of $0.550-0.785$ for admission values and $0.583-0.811$ for maximum values over the course of the first 4 consecutive days after stroke. In both instances, MRproANP showed the best discriminatory abilities to establish cardioembolic strokes (figure 2). When correcting for stroke severity expressed by the admission NIHSS score, admission values of MRproANP, MRproADM, and CTproET remained independently associated (data not shown).

\section{Discussion}

The main findings of our study are as follows: (1) The investigated biomarkers are associated with SAP and death, and they were correlated with functional outcome 3 months after stroke. (2) CPus and PCTus are independent predictors of SAP, but there is little added discrimination capacity to clinical factors. (3) The investigated biomarkers were not predicting death 3 months after stroke independent of other common risk factors. (4) Cardioembolic strokes lead to higher levels of the investigated biomarkers, with MRproANP showing the best discrimination in c-statistics.

The multivariate model for prediction of pneumonia showed excellent discrimination quality and would possibly satisfy the necessities of a clinical instrument to decide on preventive 
Table 3 Multivariate logistic regression models to predict SAP and death at day 90 after stroke

\begin{tabular}{|c|c|c|c|}
\hline & $\begin{array}{l}\text { Regression } \\
\text { coefficient }\end{array}$ & $\begin{array}{l}p \\
\text { Value }\end{array}$ & $\begin{array}{l}\text { OR } \\
(95 \% \mathrm{Cl})\end{array}$ \\
\hline \multicolumn{4}{|l|}{ Prediction of SAP } \\
\hline $\begin{array}{l}\text { NIHSS score at } \\
\text { hospital admission }\end{array}$ & 0.144 & $<0.001$ & $\begin{array}{l}1.16 \\
(1.09-1.23)\end{array}$ \\
\hline COPD & -0.801 & 0.082 & $\begin{array}{l}0.45 \\
(0.18-1.11)\end{array}$ \\
\hline Dysphagia & -1.424 & 0.003 & $\begin{array}{l}0.24 \\
(0.09-0.63)\end{array}$ \\
\hline Hypercholesterolemia & 0.762 & 0.031 & $\begin{array}{l}2.14 \\
(1.07-4.28)\end{array}$ \\
\hline CPus on day 1 & 0.009 & 0.028 & $\begin{array}{l}1.01 \\
(1.00-1.02)\end{array}$ \\
\hline PCTus on day 1 & 1.808 & 0.115 & $\begin{array}{l}6.10 \\
(0.65-57.59)\end{array}$ \\
\hline Constant & -3.402 & $<0.001$ & \\
\hline \multicolumn{4}{|l|}{$\begin{array}{l}\text { Prediction of death } \\
\text { within } 90 \mathrm{~d}\end{array}$} \\
\hline Age & 0.096 & $<0.001$ & $\begin{array}{l}1.10 \\
(1.05-1.15)\end{array}$ \\
\hline $\begin{array}{l}\text { NIHSS score at hospital } \\
\text { admission }\end{array}$ & 0.165 & $<0.001$ & $\begin{array}{l}1.18 \\
(1.11-1.26)\end{array}$ \\
\hline Constant & -11.708 & $<0.001$ & \\
\hline
\end{tabular}

Abbreviations: $\mathrm{COPD}=$ chronic obstructive pulmonary disease; $\mathrm{CPus}=\mathrm{ul}-$ trasensitive copeptin; NIHSS = NIH Stroke Scale; PCTus = ultrasensitive procalcitonin; SAP = stroke-associated pneumonia.

pharmacologic treatment. The additive value of $\mathrm{CPus}$ and PCTus to the clinical predictors of the model (NIHSS score, COPD, dysphagia, and hypercholesterolemia) was limited: a multivariate model with the same risk factors but excluding the biomarkers reached an area under the curve of 0.837 compared with 0.876 with biomarkers in the c-statistic (data not shown). The multivariate model for prediction of death 3 months after stroke was found to have excellent discrimination in the c-statistic, but was solely based on age and stroke severity.

Assuming the same distribution of risk factors and SAPs as in our studied cohort, the following numbers could be derived from an illustrative cohort of 1,000 patients with a $10 \%$ incidence of SAP: CPus showed the largest AUC in the univariate models. A value of $6.2 \mu \mathrm{g} / \mathrm{L}$ or higher would predict SAP with a sensitivity of $96 \%$, specificity of $30 \%$, PPV of $13 \%$, and a negative predictive value (NPV) of $99 \%$. If gauged for higher specificity, the cutoff could be set at $68 \mu \mathrm{g} / \mathrm{L}$, leading to a sensitivity of $28 \%$, specificity of $95 \%$, PPV of $38 \%$, and an NPV of $92 \%$. Using the latter approach (specificity of $95 \%$ ), addition of CPus and PCTus to the purely clinical model for SAP prediction improves sensitivity (23-36\%), NPV (92-93\%), and PPV (34-44\%). Further prospective data from a validation cohort are needed to confirm these predictive values.
We hereby report data on SAP and mortality prediction with CTproET and MRproANP after stroke, showing significant associations for both outcomes with both biomarkers. PCT has been associated with post-stroke infections before, ${ }^{6,7}$ although this connection could not always be reproduced. ${ }^{16}$ Our data confirm admission PCT values to be associated with SAP and outcome. Previous reports found associations of MRproADM and copeptin with stroke-associated infections ${ }^{8,12}$ and functional outcome after stroke. ${ }^{9-11}$ In a cohort of Chinese patients, copeptin predicted death in patients with ischemic stroke. Our findings corroborate these reports. However, these markers add little or no additional predictive value to purely clinical models for prediction of SAP and outcome, respectively. This is in contrast to the recent report of copeptin strongly improving outcome prediction in patients with ischemic stroke on top of clinical predictors. ${ }^{17,18}$ Taken together, these data suggest a solitary role for Copeptin as a biomarker with potential relevant additional information to clinical predictors, since the vast majority of published data suggest (especially inflammatory) biomarkers to be associated with outcome, there is rarely additional predictive value over readily available clinical information. ${ }^{19,20}$ In our cohort, severity of stroke stands out as the single strongest predictor. Fittingly, there was considerable multicollinearity between all the investigated biomarkers and between stroke severity via the NIHSS score and the biomarkers as established by Spearman correlation analysis (data not shown). Overall, the analyzed biomarkers may reflect noninfectious neuroinflammation or infections. Both of these conditions are correlated with infarction size and consequently stroke severity, as recently shown with interleukin $6 .^{21}$

Of interest, cardioembolic stroke was associated with higher levels of most of the examined biomarkers compared with other stroke etiologies. Discrimination was best for MRproANP and was independent of stroke severity in multivariate testing, possibly relating to its properties as a cardiac hemodynamic stress marker. It was previously shown to be associated with a higher risk of stroke, possibly being a marker of high risk for cardiac sources of emboli. ${ }^{22}$ Because of the design of our study, we cannot comment on other hemodynamic or other cardiac markers such as arrhythmia, heart rate variability, ejection fraction, and more. Furthermore, a comparison with other cardioembolic markers such as ( $\mathrm{N}$-terminal pro) brain natriuretic peptide would be of interest. These results do warrant further research to establish ANP as a possible laboratory biomarker for cardioembolic stroke etiology.

The strength of this analysis is the simultaneous approach with 5 biomarkers in a large sample. Associations found were very stable and appeared already when only taking laboratory results from admission into account as opposed to course of biomarkers over several days. The interpretation of these data is limited by lack of independent testing of results in a validation cohort. Furthermore, the STRAWINSKI trial randomized patients into a PCT and non-PCT group, allowing clinicians to base medical decisions on the PCT values. We deem a possible 
Figure 2 Admission and maximum MRproANP levels for patients without vs with cardioembolic stroke (A and B), as well as ROC for prediction of cardioembolic stroke for admission (C) and maximum biomarker levels (D)

A

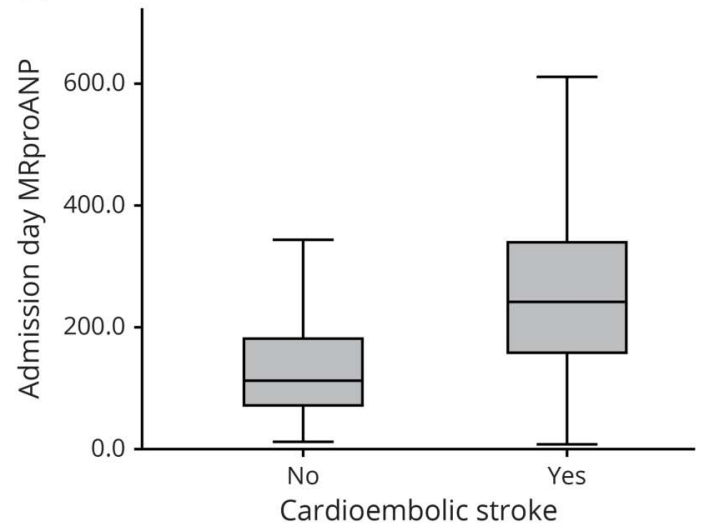

C

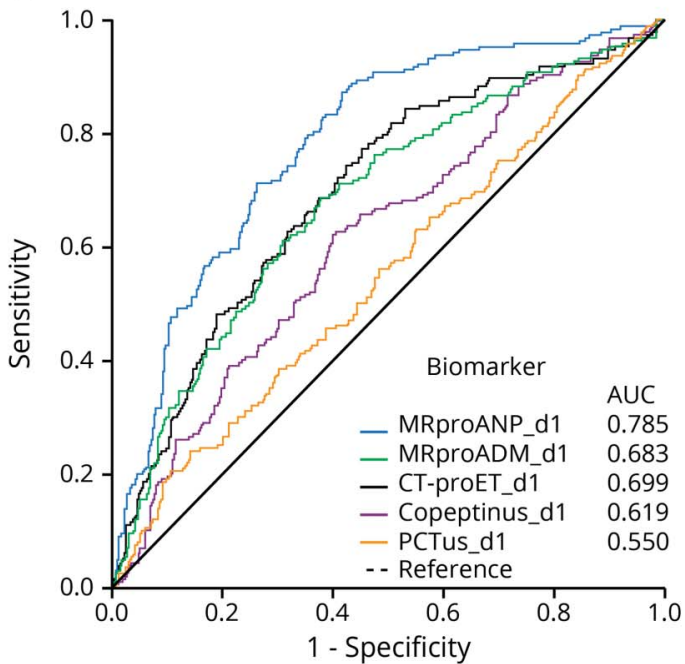

$\mathrm{B}$

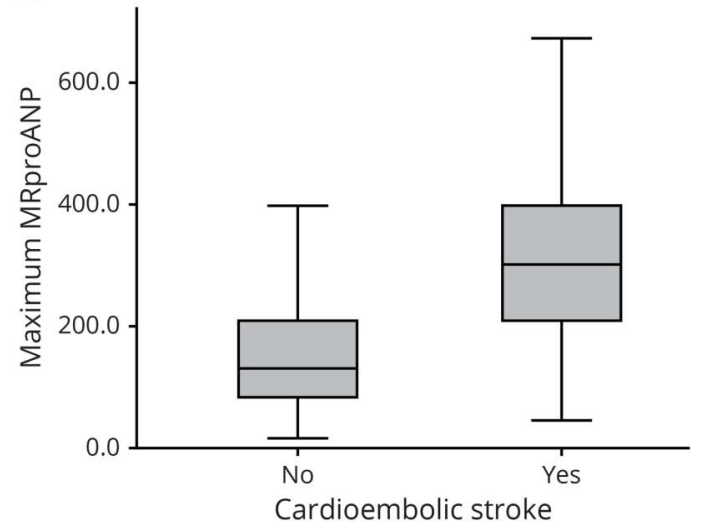

D

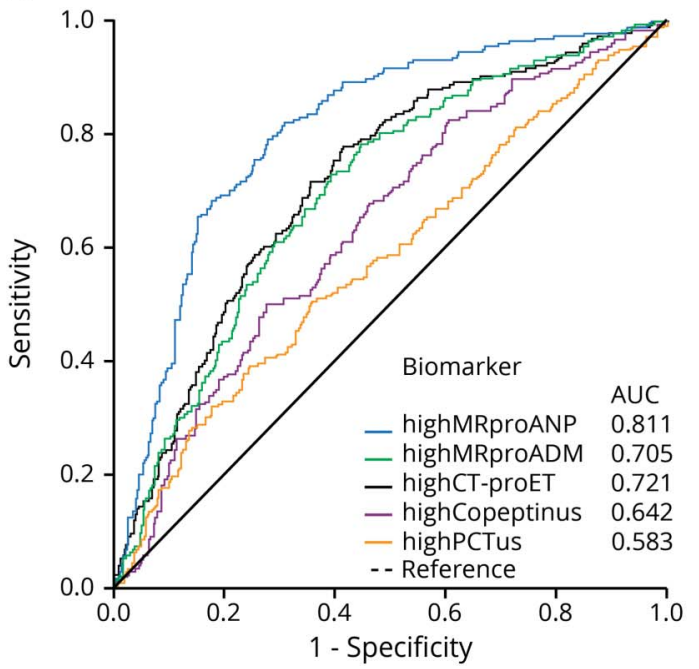

AUC = area under the curve; CTproET = C-terminal pro-endothelin; MRproADM = midregional pro-adrenomedullin; $\mathrm{MRproANP}=$ midregional pro-ANP; $\mathrm{PCT}$ $=$ ultrasensitive procalcitonin.

bias by this negligible, given that treatment guidance in the STRAWINSKI trial was shown not to be strongly driven by PCT, nor was there proof of efficient SAP prevention. ${ }^{7}$ Furthermore, we only looked at the biomarker course during the first 4 days after the event, possibly explaining differences to previous reports on the same biomarkers. Although it would have been of great interest to compare these blood-borne biomarkers with imaging findings, we only had imaging data on 94 patients, details of which have been published previously. ${ }^{21}$ Furthermore, other clinical parameters are known to partly predict the outcome of stroke that we could not account for in our analysis. The studies contributing data to this analysis did not record certain metabolic measures (such as body mass index, waist circumference, metabolic syndrome, lipid profile, and exercise), comorbidities (liver steatosis, gout, chronic kidney disease, depression, valve disorder, and coronary or peripheral artery disease) and other biomarkers (C-reactive protein and fasting glucose). However, even without these parameters, our prediction models based on the used clinical parameters are already sufficiently good to predict SAP and stroke outcome without the biomarkers.

This report corroborates the association of inflammatory and stress biomarkers with SAP, death, and functional outcome after stroke. However, the discriminatory abilities of the investigated biomarkers were either without or only minor capacity to improve prediction of SAP and functional outcome by clinical parameters. Based on our findings, we strongly recommend that future stroke biomarker research considers robust clinical parameters and possibly risk scores in $\mathrm{SAP}^{23}$ and outcome $^{18}$ prediction modeling. A further interesting finding our study suggests is that the stress biomarkers used in our study and in particular MRproANP are promising candidates for predicting cardioembolic stroke etiology. Consequently, this finding needs to be validated in further multicentre clinical trials considering other predictors for cardioembolic stroke. Such biomarkers might be also useful to detect cardioembolism in embolic stroke of undetermined source. ${ }^{24}$ 


\section{Study funding}

The PREDICT and STRAWINSKI studies were supported by German Research Foundation (Exc257, SFB-TRR84, UL423/ 1-1), German Federal Ministry of Education and Research (01EO0801), European Community FP7 (201024), Siemens Healthcare Diagnostics, and by Thermo Fisher Scientific BRAHMS GmbH, Germany. This report was supported by the German Research Foundation (SFB-TRR167). The funding bodies did not participate in the design, analysis, interpretation, or writing of this article.

\section{Disclosure}

B. Hotter, S. Hoffmann, L. Ulm, J. Montaner, A. Bustamante, C. Meisel, and A. Meisel report no disclosures relevant to this manuscript. Go to Neurology.org/NN for full disclosures.

\section{Publication history}

Received by Neurology: Neuroimmunology \& Neuroinflammation August 15, 2019. Accepted in final form January 27, 2020.

\section{Appendix Authors}

\begin{tabular}{|c|c|c|c|}
\hline Name & Location & Role & Contribution \\
\hline $\begin{array}{l}\text { Benjamin } \\
\text { Hotter, MD }\end{array}$ & $\begin{array}{l}\text { Charité - } \\
\text { Universitätsmedizin } \\
\text { Berlin, Germany }\end{array}$ & Author & $\begin{array}{l}\text { Designed and } \\
\text { conceptualized the } \\
\text { combined analysis; } \\
\text { performed statistics; } \\
\text { interpreted the } \\
\text { data; and drafted } \\
\text { and revised } \\
\text { the manuscript } \\
\text { for intellectual } \\
\text { content }\end{array}$ \\
\hline
\end{tabular}

\begin{tabular}{|c|c|c|c|}
\hline $\begin{array}{l}\text { Sarah } \\
\text { Hoffmann, } \\
\text { MD }\end{array}$ & $\begin{array}{l}\text { Charité - } \\
\text { Universitätsmedizin } \\
\text { Berlin, Germany }\end{array}$ & Author & $\begin{array}{l}\text { Designed and } \\
\text { conceptualized the } \\
\text { PREDICT study } \\
\text { and revised } \\
\text { the manuscript } \\
\text { for intellectual } \\
\text { content }\end{array}$ \\
\hline
\end{tabular}

\begin{tabular}{|c|c|c|c|}
\hline $\begin{array}{l}\text { Lena UIm, } \\
\text { MD }\end{array}$ & $\begin{array}{l}\text { Universitätsmedizin } \\
\text { Greifswald, } \\
\text { Germany }\end{array}$ & Author & $\begin{array}{l}\text { Design and } \\
\text { conceptualized the } \\
\text { STRAWINSKI trial } \\
\text { and revised the } \\
\text { manuscript for } \\
\text { intellectual } \\
\text { content }\end{array}$ \\
\hline
\end{tabular}

\begin{tabular}{|c|c|c|c|}
\hline $\begin{array}{l}\text { Joan } \\
\text { Montaner, } \\
\text { MD }\end{array}$ & $\begin{array}{l}\text { University of Seville, } \\
\text { Spain }\end{array}$ & Author & $\begin{array}{l}\text { Interpreted the } \\
\text { data and revised } \\
\text { the manuscript } \\
\text { for intellectual } \\
\text { content }\end{array}$ \\
\hline $\begin{array}{l}\text { Alejandro } \\
\text { Bustamante, } \\
\text { MD }\end{array}$ & $\begin{array}{l}\text { Vall d'Hebron } \\
\text { Institut de Recerca, } \\
\text { Barcelona, Spain }\end{array}$ & Author & $\begin{array}{l}\text { Interpreted the } \\
\text { data and revised } \\
\text { the manuscript } \\
\text { for intellectual } \\
\text { content }\end{array}$ \\
\hline $\begin{array}{l}\text { Christian } \\
\text { Meisel, MD }\end{array}$ & $\begin{array}{l}\text { Charité - } \\
\text { Universitätsmedizin } \\
\text { Berlin, Germany }\end{array}$ & Author & $\begin{array}{l}\text { Interpreted the } \\
\text { data and revised } \\
\text { the manuscript } \\
\text { for intellectual } \\
\text { content }\end{array}$ \\
\hline
\end{tabular}

Appendix (continued)

\begin{tabular}{|c|c|c|c|}
\hline Name & Location & Role & Contribution \\
\hline $\begin{array}{l}\text { Andreas } \\
\text { Meisel, MD }\end{array}$ & $\begin{array}{l}\text { Charité - } \\
\text { Universitätsmedizin } \\
\text { Berlin, Germany }\end{array}$ & Author & $\begin{array}{l}\text { Designed and } \\
\text { conceptualized the } \\
\text { combined analysis; } \\
\text { interpreted the data; } \\
\text { and drafted and } \\
\text { revised the manuscript } \\
\text { for intellectual content }\end{array}$ \\
\hline
\end{tabular}

\section{References}

1. Kumar S, Selim MH, Caplan LR. Medical complications after stroke. Lancet Neurol 2010;9:105-118.

2. Hoffmann S, Malzahn U, Harms H, et al. Development of a clinical score (A2DS2) to predict pneumonia in acute ischemic stroke. Stroke 2012;43:2617-2623.

3. Meisel C, Schwab JM, Prass K, Meisel A, Dirnagl U. Central nervous system injuryinduced immune deficiency syndrome. Nat Rev Neurosci 2005;6:775-786.

4. Meisel A, Meisel C, Harms H, Hartmann O, Ulm L. Predicting post-stroke infections and outcome with blood-based immune and stress markers. Cerebrovasc Dis 2012; 33:580-588.

5. Smith CJ, Kishore AK, Vail A, et al. Diagnosis of stroke-associated pneumonia: recommendations from the Pneumonia in Stroke Consensus Group. Stroke 2015;46: 2335-2340.

6. Fluri F, Morgenthaler NG, Mueller B, Christ-Crain M, Katan M. Copeptin, procalcitonin and routine inflammatory markers-predictors of infection after stroke. PLoS One 2012;7:e48309.

7. Ulm L, Hoffmann S, Nabavi DG, et al. The randomized controlled STRAWINSK trial: procalcitonin-guided antibiotic therapy after stroke. Front Neurol 2017;8:153.

8. Bustamante A, García-Berrocoso T, Penalba A, et al. Sepsis biomarkers reprofiling to predict stroke-associated infections. J Neuroimmunol 2017;312:19-23.

9. Seifert-Held T, Pekar T, Gattringer T, et al. Plasma midregional pro-adrenomedullin improves prediction of functional outcome in ischemic stroke. PLoS One 2013;8:e68768.

10. Zhang H, Tang B, Yin CG, et al. Plasma adrenomedullin levels are associated with long-term outcomes of acute ischemic stroke. Peptides 2014;52:44-48.

11. Xu Q, Tian Y, Peng H, Li H. Copeptin as a biomarker for prediction of prognosis of acute ischemic stroke and transient ischemic attack: a meta-analysis. Hypertens Res 2017;40:465-471.

12. Tu WJ, Ma GZ, Ni Y, et al. Copeptin and NT-proBNP for prediction of all-cause and cardiovascular death in ischemic stroke. Neurology 2017;88:1899-1905.

13. Bhandari SS, Davies JE, Struck J, Ng LL. Plasma C-terminal proEndothelin-1 (CTproET-1) is affected by age, renal function, left atrial size and diastolic blood pressure in healthy subjects. Peptides 2014;52:53-57.

14. Ulm L, Ohlraun S, Harms $\mathrm{H}$, et al. STRoke Adverse outcome is associated WIth NoSocomial Infections (STRAWINSKI): procalcitonin ultrasensitive-guided antibacterial therapy in severe ischaemic stroke patients-rationale and protocol for a randomized controlled trial. Int J Stroke 2013;8:598-603.

15. Hoffmann S, Harms H, Ulm L, et al. Stroke-induced immunodepression and dysphagia independently predict stroke-associated pneumonia - the PREDICT study. J Cereb Blood Flow Metab 2017;37:3671-3682.

16. Hug A, Mürle B, Dalpke A, Zorn M, Liesz A, Veltkamp R. Usefulness of serum procalcitonin levels for the early diagnosis of stroke-associated respiratory tract infections. Neurocrit Care 2011;14:416-422.

17. Katan M, Fluri F, Morgenthaler NG, et al. Copeptin: a novel, independent prognostic marker in patients with ischemic stroke. Ann Neurol 2009;66:799-808.

18. De Marchis GM, Dankowski T, König IR, et al. A novel biomarker-based prognostic score in acute ischemic stroke: the CoRisk score. Neurology 2019;92:e1517-e1525.

19. Whiteley W, Tian Y, Jickling GC. Blood biomarkers in stroke: research and clinical practice. Int J Stroke 2012;7:435-439.

20. Kamtchum-Tatuene J, Jickling GC. Blood biomarkers for stroke diagnosis and management. Neuromolecular Med 2019;21:344-368.

21. Hotter B, Hoffmann S, Ulm L, Meisel C, Fiebach JB, Meisel A. IL-6 plasma levels correlate with cerebral perfusion deficits and infarct sizes in stroke patients without associated infections. Front Neurol 2019;10:83.

22. Katan M, Moon YP, Paik MC, et al. Procalcitonin and midregional proatrial natriuretic peptide as markers of ischemic stroke: the northern manhattan study. Stroke 2016;47: 1714-1719.

23. Kishore AK, Vail A, Bray BD, et al. Clinical risk scores for predicting stroke-associated pneumonia: a systematic review. Eur Stroke J 2016;1:76-84.

24. García-Berrocoso T, Palà E, Consegal $\mathrm{M}$, et al. Cardioembolic ischemic stroke gene expression fingerprint in blood: a systematic review and verification analysis. Transl Stroke Res 2019;4422:1-11. 


\section{Neurology \\ Neuroimmunology \& Neuroinflammation}

Inflammatory and stress markers predicting pneumonia, outcome, and etiology in patients with stroke: Biomarkers for predicting pneumonia, functional outcome, and death after stroke

Benjamin Hotter, Sarah Hoffmann, Lena Ulm, et al.

Neurol Neuroimmunol Neuroinflamm 2020;7;

DOI 10.1212/NXI.0000000000000692

This information is current as of February 25, 2020

Updated Information \&

Services

References

Subspecialty Collections

Permissions \& Licensing

Reprints including high resolution figures, can be found at:

http://nn.neurology.org/content/7/3/e692.full.html

This article cites 24 articles, 3 of which you can access for free at: http://nn.neurology.org/content/7/3/e692.full.html\#\#ref-list-1

This article, along with others on similar topics, appears in the following collection(s):

All Cerebrovascular disease/Stroke

http://nn.neurology.org//cgi/collection/all_cerebrovascular_disease_str oke

All Immunology

http://nn.neurology.org//cgi/collection/all_immunology

Information about reproducing this article in parts (figures,tables) or in its entirety can be found online at:

http://nn.neurology.org/misc/about.xhtml\#permissions

Information about ordering reprints can be found online:

http://nn.neurology.org/misc/addir.xhtml\#reprintsus

Neurol Neuroimmunol Neuroinflamm is an official journal of the American Academy of Neurology.

Published since April 2014, it is an open-access, online-only, continuous publication journal. Copyright

Copyright (C) 2020 The Author(s). Published by Wolters Kluwer Health, Inc. on behalf of the American

Academy of Neurology.. All rights reserved. Online ISSN: 2332-7812.

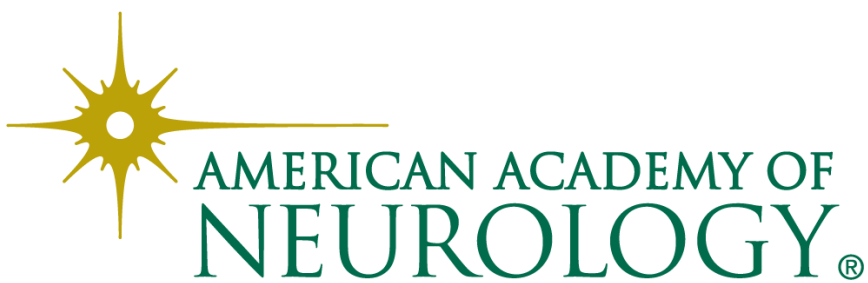

